\title{
Characterization and Optimization of Biosynthesis of Bioactive Secondary Metabolites Produced by Streptomyces sp. 8812
}

\author{
ALEKSANDRA RAJNISZ, ADAM GUŚPIEL, MAGDALENA POSTEK, JOANNA ZIEMSKA, \\ ANNA LASKOWSKA, DANIEL RABCZENKO and JOLANTA SOLECKA*
}

National Institute of Public Health-National Institute of Hygiene, Warsaw, Poland

Submitted 3 June 2015, revised 20 November 2015, accepted 26 November 2015

\begin{abstract}
The nutritional requirements and environmental conditions for a submerged culture of Streptomyces sp. 8812 were determined. Batch and fed-batch Streptomyces sp. 8812 fermentations were conducted to obtain high activity of secondary metabolites. In the study several factors were examined for their influence on the biosynthesis of the active metabolites-7-hydroxy-6-oxo-2,3,4,6-tetrahydroisoquinoline-3-carboxyl acid $\left(\mathrm{C}_{10} \mathrm{H}_{9} \mathrm{NO}_{4}\right)$ and $\mathrm{N}$-acetyl-3,4-dihydroxy-L-phenylalanine $\left(\mathrm{C}_{11} \mathrm{H}_{13} \mathrm{NO}_{5}\right)$ : changes in medium composition, $\mathrm{pH}$ of production medium, various growth phases of seed culture, amino acid supplementation and addition of anion exchange resin to the submerged culture. Biological activities of secondary metabolites were examined with the use of DD-carboxypeptidase 64-575 and horseradish peroxidase. Streptomyces sp. 8812 mycelium was evaluated under fluorescent microscopy and respiratory activity of the strain was analyzed. Moreover, the enzymatic profiles of the strain with the use of Api ${ }^{\oplus} \mathrm{ZYM}$ test were analyzed and genetic analysis made. Phylogenetic analysis of Streptomyces sp. 8812 revealed that its closest relative is Streptomyces capoamus JCM 4734 (98\%), whereas sequence analysis for 16S rRNA gene using NCBI BLAST algorithm showed 100\% homology between these two strains. Biosynthetic processes, mycelium growth and enzyme inhibitory activities of these two strains were also compared.
\end{abstract}

Ke y wo r d s: Streptomyces sp. 8812, biologically active compounds, media optimization, submerged cultures

\section{Introduction}

Streptomyces are Gram-positive bacteria with a remarkably complex developmental cycle. These bacteria are isolated from soil and water in all ecosystems. Streptomyces are producers of many secondary metabolites with a wide range of activities, e.g. antimicrobial, antitumor and immunosuppressive (Hopwood, 2007). Bioactive secondary metabolites are mostly isolated from submerged cultures, often in discreet amounts. One of the strategies to improve production of secondary metabolites is optimization of chemical and physical conditions of the submerged culture. This process involves defining the composition of the production medium, temperature and $\mathrm{pH}$ value (Genilloud et al., 2011).

In this work, the authors present results of a set of experiments performed in submerged cultures for Streptomyces sp. 8812 isolated from Brazilian soil. The described research is a continuation of the work on the strain Streptomyces sp. 8812 and its metabolites. Previously, two bioactive metabolites with antibacterial activity were isolated and characterized (Solecka et al., 2009a; 2009b; 2012a). One of them had a novel structure. The chemical structure and biological and physico-chemical properties of two secondary metabolites produced by Streptomyces sp. 8812 have been determined. The first metabolite is an isoquinoline alkaloid, 7-hydroxy-6-oxo-2,3,4,6-tetrahydroisoquinoline-3-carboxyl acid $\left(\mathrm{C}_{10} \mathrm{H}_{9} \mathrm{NO}_{4}\right)$, with molecular mass of 207.06 Da. The second Streptomyces sp. 8812 metabolite is a protoalkaloid, $\mathrm{N}$-acetyl-3,4-dihydroxyL-phenylalanine $\left(\mathrm{C}_{11} \mathrm{H}_{13} \mathrm{NO}_{5}\right)$ with molecular mass of 239.07 $\mathrm{Da}$. Both compounds exhibit antibacterial properties, have the ability to inhibit DD-carboxypeptidase 64-575 activity and are stable to $\beta$-lactamase activity. Their chemical structures may serve as lead compounds for modifications enhancing their biological activities (Solecka et al., 2009a; 2009b; 2012a; 2012b).

In the present study, the authors defined the optimum composition and $\mathrm{pH}$ value of the production medium for bioactive secondary metabolites biosynthesis. The seed cultures at various growth phases were tested. A fed-batch strategy was used to study the effect of different amino acids on secondary metabolites

* Corresponding author: J. Solecka, National Institute of Public Health-National Institute of Hygiene, Warsaw, Poland; e-mail: jsolecka@pzh.gov.pl 
activities. The authors examined whether addition of a resin into the production medium has an effect on the biosynthesis of biologically active compounds. Biological activity of the metabolites was studied under the guidance of DD-carboxypeptidase 64-575 and horseradish peroxidase inhibition reaction. Selected methods were chosen due to their high sensitivity which is significant in the case of secondary metabolites produced in very small quantities (hundredths of permille).

In further steps, genetic classification of Streptomyces sp. 8812 using $16 \mathrm{~S}$ rRNA analysis was performed. Mycelium viability and respiratory activity of Streptomyces sp. 8812 during submerged culture was observed and characterized by fluorescent microscopy. The Api ${ }^{\oplus}$ ZYM test was used for biochemical characterization of mycelium during fermentation.

\section{Experimental}

\section{Materials and Methods}

Microorganism. Streptomyces sp. 8812 is a strain isolated from Brazilian soil. The strain is deposited in the Polish Collection of Microorganisms in Wroclaw, with an accession number B/00017. The 16S rRNA gene sequence of Streptomyces sp. 8812 has GenBank accession number KT951721.

Morphological and carbon utilization properties of Streptomyces sp. 8812 were described in previous paper (Solecka et al., 2009a). Spores of Streptomyces sp. 8812 were stored at $-70^{\circ} \mathrm{C}$.

Media and growth conditions. Streptomyces sp. 8812 was maintained on yeast-malt agar (ISP2) slants (Shirling and Gottlieb, 1966). The seed medium and initial production medium $(\mathrm{M})$ consisted of $(\mathrm{g} / \mathrm{l})$ : lactose 10.0, yeast extract 5.0, corn steep liquor (CSL) 10.0, Bacto $^{\text {tw }}$ peptone 4.0, Bacto ${ }^{\text {Tm }}$ tryptone $17.0, \mathrm{MgCl} 2 \times 7 \mathrm{H}_{2} \mathrm{O}$ $0.5, \mathrm{KH}_{2} \mathrm{PO}_{4} 2.0, \mathrm{~K}_{2} \mathrm{HPO}_{4} 4.0, \mathrm{CaCO}_{3} 3.0$ and microelements: $\mathrm{MnSO}_{4} \times \mathrm{H}_{2} \mathrm{O} 0.002, \mathrm{FeSO}_{4} \times 7 \mathrm{H}_{2} \mathrm{O} 0.01$, $\mathrm{ZnSO}_{4} \times 7 \mathrm{H}_{2} \mathrm{O} 0.01, \mathrm{CoCl}_{2} 0.0008, \mathrm{CuSO}_{4} \times 5 \mathrm{H}_{2} \mathrm{O} 0.001$. After sterilization, $\mathrm{pH}$ was adjusted to 6.7 value.

In $\mathrm{pH}$-optimization experiment $\mathrm{pH}$ of medium $\mathrm{M}$ after sterilization was adjusted to several values: 5.5, 5.9, $6.3,6.7,7.0,7.4,7.8$ and was measured every 24 hours during fermentation.

Slants with Streptomyces sp. 8812 were incubated at $28^{\circ} \mathrm{C}$ for 10 days. Spores from fresh solid culture were transferred into $35 \mathrm{ml}$ of the medium $\mathrm{M}$ in $500 \mathrm{ml}$ shake flasks. The seed cultures were incubated in a rotary shaker at $220 \mathrm{rpm}$ for: 24,48 or 72 hours at $28^{\circ} \mathrm{C}$. Then, $3.5 \mathrm{ml}$ of seed cultures were transferred to $35 \mathrm{ml}$ of production medium. The biosynthesis process was conducted at $220 \mathrm{rpm}$ for $120 \mathrm{~h}$ at $28^{\circ} \mathrm{C}$. Samples were taken every $24 \mathrm{~h}$. Yeast-malt broth was used for myce- lium growth for genetic analysis. Cultures for genetic analysis were incubated in a rotary shaker at $220 \mathrm{rpm}$ for $24 \mathrm{~h}$ at $28^{\circ} \mathrm{C}$.

Optimization of the production medium. Several nitrogen sources, like soybean flour, yeast extract, Bacto ${ }^{\mathrm{TM}}$ peptone, Bacto ${ }^{\mathrm{TM}}$ tryptone, neopeptone, were tested in a set of experiments (Table I). Medium M was modified in three ways: deletion or replacement, and adjustment of the component(s) concentration. Concentrations of macroelements, such as $\mathrm{K}^{+}, \mathrm{Mg}^{2+}, \mathrm{Ca}^{2+}$, and microelements were constant in all media. The percentage of $\mathrm{C}$ and $\mathrm{N}$ values in all tested media was estimated on the basis of Becton Dickinson (BD) tables (BD Biosciences, 2006), for CSL (Keller and Heckmann LPP, 2006). The initial $\mathrm{C} / \mathrm{N}$ values varied from 0.11 to 2.07 .

Statistical method. The most significant component of the production medium was estimated using a statistical method. Each parameter (carbon and nitrogen source in the production medium) was characterized by mass percentage composition. Correlation between the share of each substrate in overall mass of medium and the DD-carboxypeptidase 64-575 inhibitory activity at $120 \mathrm{~h}$ was assessed using Spearman correlation coefficient and test of its significance. Calculations were performed using R 3.0.1 statistical software (R Foundation for Statistical Computing, 2013).

Determination of biomass growth. One $\mathrm{ml}$ of submerged cultures was taken every $24 \mathrm{~h}$. Probes were centrifuged and the biomass was washed twice with distilled water. Dry biomass was obtained after incubation at $110^{\circ} \mathrm{C}$ in dryer (Pol-Eco). The drying process was finished when the biomass weight was stable.

Determination of secondary metabolites activities. To determine the optimum conditions for conducting the submerge culture of Streptomyces sp. 8812, activity of secondary metabolites was measured. DD-carboxypeptidase 64-575 from Saccharopolyspora erythraea 64-575 (Solecka and Kurzątkowski, 1999; Solecka et al., 2003) and horseradish peroxidase (HRP, SigmaAldrich) were used for enzymatic assays to determine the activity of secondary metabolites.

Inhibition of DD-carboxypeptidase 64-575 activity. The assay was done according to the method previously described by Frère et al. (1976), with modifications (Adam et al., 1990; 1991; Solecka et al., 2003). The reaction mixture consisted of: $5 \mu \mathrm{l}$ of DD-carboxypeptidase $64-575,5 \mu \mathrm{l}$ of $10 \mathrm{mM}$ 2-((2-benzamidopropanol) thio)acetic acid, $5 \mu \mathrm{l}$ of supernatant and $85 \mu \mathrm{l}$ of $0.1 \mathrm{M}$ phosphate buffer $\mathrm{pH}$ 8.0. All samples were triplicated. Absorbance was measured at $250 \mathrm{~nm}$ for $1200 \mathrm{~s}$ at $37^{\circ} \mathrm{C}$ (Jasco V-630). DD-carboxypeptidase 64-575 inhibition was calculated using the formula shown below:

$$
\begin{array}{r}
D D \text { - carboxypeptidase } 64-575 \text { inhibition }[\%]= \\
=100-\left(\frac{A_{2}-A_{3}}{A_{0}-A_{1}} \times 100\right)
\end{array}
$$


The initial value of the absorbance of the enzyme control is $\mathrm{A}_{0}$ whereas final value of the absorbance of the enzyme control is $A_{1}$. The initial value of the absorbance of the supernatant sample is $A_{2}$ and final value of the absorbance of the supernatant sample is $\mathrm{A}_{3}$. Due to the method limitation, results were measured with $5 \%$ error.

Inhibition of HRP activity. The assay was done according to the method of Lehmann et al. (1974) with modifications (Chance and Maehly, 1955). The reaction mixture consisted of: $37.5 \mu \mathrm{l}$ of $0.01 \mathrm{M}$ phosphate buffer $\mathrm{pH}$ 8.0, $2.5 \mu \mathrm{l}$ of Streptomyces sp. 8812 submerged culture supernatant, $5 \mu \mathrm{l}$ of $0.025 \mathrm{mg} / \mathrm{ml} \mathrm{HRP}$, $5 \mu \mathrm{l}$ of $1.26 \mathrm{mg} / \mathrm{ml} \mathrm{o}$-dianisidine and $10 \mu \mathrm{l}$ of $0.480 \mathrm{mM}$ hydrogen peroxide in $0.01 \mathrm{M}$ phosphate buffer $\mathrm{pH}$ 8.0. After $10 \mathrm{~min}$ incubation at $37^{\circ} \mathrm{C}, 100 \mu \mathrm{l}$ of watermethanol-sulfuric acid (5:5:6 v/v) was added and incubated for further $10 \mathrm{~min}$ at room temperature. The absorbance was measured at $540 \mathrm{~nm}$ (Fluostar Omega, LABTECH). HRP inhibition was calculated using the formula shown below:

$$
\text { HRP inhibition }[\%]=\frac{A_{\text {control }}-A_{\text {supernatant }}}{A_{\text {control }}} \times 100
$$

The absorbance for the control is $A_{\text {control }}$ whereas the absorbance in the presence of a supernatant is $A$ The positive control for enzymatic activity measurements consisted of $2.5 \mu \mathrm{l}$ of water instead of supernatant and an analogous blank contained phosphate buffer instead of hydrogen peroxide. Sample, control and related blanks were triplicated and carried out under the same condition on the same microliter plate.

Culture supplementation with amino acids. Different concentrations: $0.1,1,10$ and $100 \mathrm{mM}$ of L-tyrosine, L-tryptophan and L-phenylalanine were separately used in secondary metabolites activity tests. One $\mathrm{ml}$ of each concentration was added to shake-flasks cultures every $24 \mathrm{~h}$ till the end of fermentation.

Addition of anion exchange resin to production medium. Two g of anion exchange resin IRA-400 $(\mathrm{OH})$ (Supelco) was equilibrated twice with $50 \mathrm{ml}$ of $2.0 \mathrm{M}$ acetic acid and rinsed with sterile water till $\mathrm{pH}$ value reached 7.0. Resin IRA-400 (2.0 g) was added to 24 -h or 48-h old shake-flask cultures. All probes were incubated for $24 \mathrm{~h}$. Next, the resin was removed from flasks and cultivation was continued till $120 \mathrm{~h}$. The resin was rinsed with distilled water and eluted using $100 \mathrm{ml}$ of $2.0 \mathrm{M}$ acetic acid. Material eluted from the resin was lyophilized and compound activity was measured $(7 \mu \mathrm{lof} 1 \mathrm{mg}$ lyophilizate in $100 \mu \mathrm{l}$ of $0.01 \mathrm{M}$ phosphate buffer $\mathrm{pH} 8.0$ ).

Genetic analysis. Genomic DNA of Streptomyces sp. 8812 was obtained using the Wizard ${ }^{\oplus}$ Genomic DNA Purification Kit (Promega). Nearly complete 16S rRNA gene ( $\sim 1500$ nucleotides [nt]) was amplified using universal primers: $\mathrm{pHr}$ and $\mathrm{pAf}$ (Edwards et al., 1989). The amplified product was purified with Wizard ${ }^{\oplus}$ SV Gel and PCR Clean-Up System (Promega). The 16S rRNA gene was sequenced with an automated DNA sequencing system (ABI 3730) and BigDye terminator cycle sequencing kit (Applied Biosystems). Primers used for sequencing are listed by Coenye et al. (1999).

A BLAST search service of the GenBank database was used to establish bacterial species most similar to Streptomyces sp. 8812 based on the 16S rRNA gene sequence. A phylogenetic tree was constructed using the neighbor-joining, maximum-likelihood, maximumparsimony tree-making algorithms. An evolutionary distance matrix was generated. Confidence values of branches of the phylogenetic tree were determined in a bootstrap analysis based on 1.000 resampling of the neighbor-joining dataset.

Mycelium observation under fluorescent microscopy. Streptomyces sp. 8812 mycelium viability was determined with LIVE/DEAD ${ }^{\circledR}$ Bac-Light ${ }^{\text {TM }}$ Bacterial Viability Kit (Invitrogen). Centrifuged mycelium samples from submerged cultures were washed gently two times with sterile $0.2 \% \mathrm{NaCl}$ solution. Then, the harvested mycelium was stained according to the Molecular Probes protocol $\left(15 \mathrm{~min}\right.$ at $37^{\circ} \mathrm{C}$ in dark). The SYTO 9 green fluorescent stain labels cells with intact and damaged membranes. Propidium iodide (PI) only enters bacteria with damaged membranes and affects SYTO 9 fluorescence. Thus, live bacteria appear fluorescent green whereas dead bacteria appear red. The stained mycelium was observed with fluorescent microscope OPTA-TECH MN-800FL immediately after preparation.

The respiration activity of Streptomyces sp. 8812 was determined with 5-cyano-2,3-bis(4-methylphenyl)$2 \mathrm{H}$-tetrazolium chloride (CTC) (Sigma-Aldrich). During cell respiration CTC is reduced intracellularly to the red fluorescent formazan crystals (CTF). The final CTC concentration in the probe was $5.0 \mathrm{mM}$. Samples were incubated for $3 \mathrm{~h}$ at $37^{\circ} \mathrm{C}$ in the dark, fixed with $2 \%$ formalin (final concentration) and washed twice with sterile $0.2 \% \mathrm{NaCl}$ solution. Afterwards, probes were observed under the fluorescent microscope OPTA-TECH MN-800FL. Observed pellets were documented on merged photos showing the whole mycelium (light microscopy) and red fluorescent formazan crystals (fluorescent microscopy).

Analysis of enzyme profiles using the api ${ }^{\circledast}$ ZYM test. Mycelium probes from seed and production cultures of Streptomyces sp. 8812 conducted in medium M were characterized with api ${ }^{\oplus}$ ZYM tests (bioMérieux SA, France). This semi-quantitative micromethod is designed for determining enzymatic activities. It consists of api ${ }^{\circledast}$ ZYM stripes with enzymatic substrates, incubation boxes, ZYM A and ZYM B reagents. The tested enzymes include phosphatases, esterases, lipases, arylamidases, trypsin, $\alpha$-chymotrypsin, phosphohydrolase, 
$\alpha$-, $\beta$-galactosidases, $\beta$-glucuronidase, $\alpha$-, $\beta$-glucosidases, $\mathrm{N}$-acetyl- $\beta$-glucosaminidase, $\alpha$-mannosidase and $\alpha$-fucosidase. Mycelium from the submerged culture was harvested by centrifugation and washed twice with sterile $0.2 \% \mathrm{NaCl}$. Mycelium suspension adjusted to 5-6 McFarland turbidity standard was added to the wells. After $4-4.5-\mathrm{h}$ incubation at $37^{\circ} \mathrm{C}$ one drop of ZYM A and ZYM B were added to each well. Intensity of the colors that appeared in the wells was estimated on a 1-5 scale, according to the protocol. Pseudomonas aeruginosa ATCC 27853 was used as a quality control strain.

\section{Results and Discussion}

\section{Medium optimization for bioactive metabolites production by Streptomyces sp. 8812}

Utilization of nitrogen sources. To establish the optimal conditions of Streptomyces sp. 8812 fermentation for secondary metabolites biosynthesis, the production medium $\mathrm{M}$ was modified in 17 manners (Table I), with respect to nitrogen sources. The DD-carboxypeptidase 64-575 inhibitory activities of secondary metabolites produced in the different media were compared to those synthesized during Streptomyces sp. 8812 fermentation in medium M (Table I). Positive values of correlation coefficients were achieved for soybean flour, Bacto ${ }^{\mathrm{TM}}$ peptone, yeast extract, CSL, neopeptone and soytone, indicating that high contents of these nitrogen sources in the medium lead to enhanced production of DD-carboxypeptidase 64-575 inhibitors (Table II). Addition of soybean flour to the medium (medium 11 and 17) had a positive impact on the level of the produced bioactive metabolites. Bacto ${ }^{\mathrm{TM}}$ peptone was added to each medium, except medium 4 and 13, and its increasing amounts had a favorable effect on the production of active metabolites. Similar influence was noted for yeast extract, which was present in all media, except 4 and 12; its influence on production of biologically active substances was proportional to its content in the medium.

A negative value of correlation coefficient was obtained for Bacto ${ }^{\text {Tx }}$ tryptone (Table II), which was present in all tested media. High amounts of this nitrogen source in the medium, impaired enzyme inhibitory activities. For media 2 and 3, containing $5 \mathrm{~g}$ of Bacto ${ }^{\text {rm }}$ tryptone, which were additionally enriched with $5 \mathrm{~g}$ of neopeptone and $5 \mathrm{~g}$ of soytone, respectively, secondary metabolites activities were as high as after fermentation in medium M. However, Bacto ${ }^{\mathrm{TM}}$ tryptone, when used as the only source of nitrogen in the production medium, was not sufficient for secondary metabolites production (medium 4). A decrease in inhibitory activity of bioactive metabolites was also noticed when the amounts of Bacto $^{\mathrm{TM}}$ tryptone, Bacto ${ }^{\mathrm{TM}}$ peptone and yeast extract in the production medium were reduced by 50\% (medium 5). In comparison to the composition of medium $\mathrm{M}$, increasing the amounts of these three components by $50 \%$ (medium 6 ) did not enhance biosynthesis of bioactive metabolites. Additionally, when the yeast extract and Bacto $^{\mathrm{TM}}$ peptone were separately removed from the initial medium (medium 12 and 13, respectively), a decrease in secondary metabolites activity was also observed.

Further on, the influence of CSL in the production media on the biosynthesis of enzyme inhibitors was examined. CSL ( $10 \mathrm{~g} / \mathrm{l})$ was found to be an important component of medium $\mathrm{M}$ in obtaining biologically active secondary metabolites. Elimination of CSL (medium 7) resulted in low inhibitory metabolites activities. As a rich source of amino acids, vitamins and glucose, CSL is often used as a component of microbial fermentation broth (De Azeredo et al., 2006; Zou et al., 2009). It is produced in the maize steeping process. The low costs of CSL production are an important factor standing in favor for its utilization in pharmaceutical industry (De Azeredo et al., 2006).

DD-carboxypeptidase 64-575 inhibitory activities were comparable to the levels observed for medium $\mathrm{M}$ cultures after fermentation in medium 11, which contained a reduced amount of Bacto ${ }^{\text {TM }}$ tryptone (from $17 \mathrm{~g}$ to $5 \mathrm{~g}), 20 \mathrm{~g}$ of soybean flour and which was deprived of CSL. It was shown that soybean flour is more nutritional for bacteria in submerged cultures than other soya extracts (Ortiz et al., 2007). Overall, the conducted studies show clearly the great importance of complex nitrogen sources on production of bioactive metabolites by Streptomyces sp. 8812 . Moreover, statistical analysis revealed that higher amounts of each nitrogen source (except Bacto ${ }^{\text {Tu }}$ tryptone) tested had a positive impact on the production of bioactive metabolites.

Utilization of carbon sources. The influence of $a$-lactose in the production media on the biosynthesis of enzyme inhibitors was examined. Statistical analysis showed that higher DD-carboxypeptidase inhibitory activity was observed when the percentage of $\alpha$-lactose (rho $=-0.489, \mathrm{P}=0.040, \mathrm{n}=18$ ) was lower in the production medium (Table II). Therefore, increase of the lactose content to $15 \mathrm{~g}$ (medium 15) did not improve the activity of bioactive metabolites.

The relationship between the $\mathrm{C} / \mathrm{N}$ ratio values in the different media and the activity of secondary metabolites (Table I) was analyzed. Efficient production of bioactive metabolites during fermentation processes was determined to occur at moderate $\mathrm{C} / \mathrm{N}$ ratio values for some Streptomyces strains (Zhinan and Peilin, 1999). Statistically significant correlation for the value of $\mathrm{C} / \mathrm{N}$ ( $\mathrm{rho}=-0.508 ; \mathrm{P}=0.031, \mathrm{n}=18$ ) (Table II) was observed. In spite of similar initial $\mathrm{C} / \mathrm{N}$ ratio values 
Table I

The 17 modifications of initial medium $\mathrm{M}$.

\begin{tabular}{|c|c|c|c|c|c|c|c|c|c|c|}
\hline & a-Lactose & $\begin{array}{c}\text { Soybean } \\
\text { flour }\end{array}$ & $\begin{array}{c}\text { Bacto } \\
\text { Peptone }\end{array}$ & $\begin{array}{c}\text { Yeast } \\
\text { Extract }\end{array}$ & $\begin{array}{c}\text { Bacto }^{\text {mix }} \\
\text { Tryptone }\end{array}$ & $\begin{array}{c}\text { Corn Steep } \\
\text { Liquor (CSL) }\end{array}$ & Neopeptone & Soytone & C/N* $^{*}$ & $\begin{array}{c}\text { Activity at } \\
120 \mathrm{~h}(\%)^{* * *}\end{array}$ \\
\hline $\mathbf{M}$ & 10 & - & 4 & 5 & 17 & 10 & - & - & 1.27 & 100 \\
\hline $\mathbf{1}$ & 10 & - & 4 & 5 & 5 & 10 & - & - & 2.04 & 65.2 \\
\hline $\mathbf{2}$ & 10 & - & 4 & 5 & 5 & 10 & 5 & - & 1.62 & 100 \\
\hline $\mathbf{3}$ & 10 & - & 4 & 5 & 5 & 10 & - & 5 & 1.92 & 100 \\
\hline $\mathbf{4}$ & 10 & - & - & - & 17 & - & - & - & 1.87 & 50.2 \\
\hline $\mathbf{5}$ & 10 & - & 2 & 2.5 & 8.5 & 10 & - & - & 2.07 & 39.1 \\
\hline $\mathbf{6}$ & 10 & - & 6 & 7.5 & 25 & 10 & - & - & 0.93 & 100 \\
\hline $\mathbf{7}$ & 10 & - & 4 & 5 & 17 & - & - & - & 1.34 & 72 \\
\hline $\mathbf{8}$ & 10 & - & 4 & 5 & 17 & 15 & - & - & 1.24 & 87.5 \\
\hline $\mathbf{9}$ & 10 & - & 4 & 5 & 17 & 10 & - & 5 & 1.27 & 79.1 \\
\hline $\mathbf{1 0}$ & 10 & - & 4 & 5 & 17 & 10 & 5 & - & 1.09 & 87.5 \\
\hline $\mathbf{1 1}$ & 10 & 20 & 4 & 5 & 5 & - & - & - & $\mathrm{nc}$ & 100 \\
\hline $\mathbf{1 2}$ & 10 & - & 4 & - & 17 & 10 & - & - & 1.36 & 67.2 \\
\hline $\mathbf{1 3}$ & 10 & - & - & 5 & 17 & 10 & - & - & 1.49 & 65.5 \\
\hline $\mathbf{1 4}$ & - & - & 4 & 5 & 17 & 10 & - & - & 0.26 & 100 \\
\hline $\mathbf{1 5}$ & 15 & - & 4 & 5 & 17 & 10 & - & - & 1.77 & 95.5 \\
\hline $\mathbf{1 6}$ & - & - & 4 & 5 & 17 & - & - & - & 0.11 & 66.7 \\
\hline $\mathbf{1 7}$ & - & 10 & 4 & 5 & 5 & 10 & - & - & $\mathrm{nc}$ & 100 \\
\hline
\end{tabular}

* $\mathrm{C} / \mathrm{N}$ means percentage contribution of $\mathrm{C}$ and $\mathrm{N}$ in medium

$* *$ nc means not calculated

$* * *$ activity is a percent of DD-carboxypeptidase 64-575 inhibition

of medium $M$ (1.27), 7 (1.34), 8 (1.24), 9 (1.27) and 12 (1.36), medium $M$ gave the highest activity of secondary metabolites after fermentation. In the light of the above, it seems that for Streptomyces sp. 8812 nitrogen sources were more important than $\alpha$-lactose for biosynthesis of bioactive metabolites.

Characterization of mycelium growth and biosynthesis of secondary metabolites - DD-carboxypepti-

Table II

Correlation between the percentage share of each substrate in overall mass of medium and the DD-carboxypeptidase 64-575 inhibitory activity at $120 \mathrm{~h}$.

\begin{tabular}{|c|c|c|c|}
\hline & $\mathrm{N}$ & $\begin{array}{c}\text { Spearman } \\
\text { correlation } \\
\text { coefficient (rho) }\end{array}$ & P-value \\
\hline$a$-Lactose & 18 & -0.489 & 0.040 \\
\hline Soybean flour & 18 & 0.386 & 0.114 \\
\hline Bacto $^{\text {tm }}$ Peptone & 18 & 0.338 & 0.170 \\
\hline Yeast extract & 18 & 0.302 & 0.224 \\
\hline Bacto $^{\text {ns }}$ Tryptone & 18 & -0.136 & 0.590 \\
\hline Corn Steep Liquor & 18 & 0.014 & 0.956 \\
\hline Neopeptone & 18 & 0.204 & 0.418 \\
\hline Soytone & 18 & 0.154 & 0.542 \\
\hline $\mathrm{C} / \mathrm{N}$ & 18 & -0.508 & 0.031 \\
\hline
\end{tabular}

dase 64-575 inhibitors. The most intensive Streptomyces sp. 8812 mycelium growth rate was observed during the first 24 hours of fermentation $(0.38 \mathrm{mg} / \mathrm{ml} / \mathrm{h})$. Mycelium biomass concentration after $24 \mathrm{~h}$ was maintained at a similar level until the end of fermentation (to 144 h). Production of DD-carboxypeptidase 64-575 inhibitors began at the same time as biomass formation (Table III) and reached the maximum level after $48 \mathrm{~h}$. The overlap of trophophase (intensive growth) and idiophase (secondary metabolites formation) resulted in an uniphasic culture. It was shown in other

Table III

DD-carboxypeptidase 64-575 inhibitory activity of Streptomyces sp. 8812 metabolites and biomass concentration during $144 \mathrm{~h}$ of cultivation.

\begin{tabular}{|c|c|c|}
\hline $\begin{array}{c}\text { Time } \\
\text { of cultivation } \\
(\mathrm{h})\end{array}$ & $\begin{array}{c}\text { DD-carboxypeptidase } \\
\text { 64-575 inhibition } \\
(\%)\end{array}$ & $\begin{array}{c}\text { Mycelium biomass } \\
\text { concentration } \\
(\mathrm{mg} / \mathrm{ml})\end{array}$ \\
\hline 24 & 70 & 9.14 \\
\hline 48 & 82.6 & 6.3 \\
\hline 72 & 87.4 & 5.5 \\
\hline 96 & 90 & 5.6 \\
\hline 120 & 92.4 & 5.4 \\
\hline 144 & 90 & 5.7 \\
\hline
\end{tabular}


studies that when defined media support the rapid growth of Streptomyces coelicolor A3(2), the strain produced actinorhodin in a fully biphasic fermentation profile. Many environmental factors (media composition, temperature, etc.) determine the correlation between biomass growth and bioactive metabolite production (Liao et al., 1995).

Optimization of $\mathrm{pH}$ value of the production media. The $\mathrm{pH}$ value during the fermentation process affects bacterial cell growth and bioactive product formation, as well as stimulates or inhibits the activity of enzymes (Chen et al., 2011). HRP inhibitory activities of secondary metabolites were tested during Streptomyces sp. 8812 fermentation in medium $\mathrm{M}$ at different initial $\mathrm{pH}$ values. Highest metabolites activities were obtained when initial $\mathrm{pH}$ values of the media did not exceed 7.4 (Supplementary Fig. 1(A)S).

During the first 24 hours of fermentation the $\mathrm{pH}$ value rose from 6.7 to 8.2 , and maintained at similar level to the end of the cultivation (Supplementary Fig. 1(B)S). Due to the glycolysis process in bacterial cells and the release of pyruvate, the $\mathrm{pH}$ value typically decreases during the first $24 \mathrm{~h}$ of fermentation (Desai et al., 2002; Chen et al., 2011). In the present studies, the $\mathrm{pH}$ value increased during the first $24 \mathrm{~h}$ of fermentation. Possibly, Streptomyces sp. 8812 showed a low intensity of glycolysis process under submerged culture conditions. Perhaps, this strain intensively utilizes peptides and amino acids as nitrogen and carbon sources, generating ammonia as a side product which causes the increase of $\mathrm{pH}$ value. Furthermore, Streptomyces sp. 8812 biomass growth and bioactive secondary metabolites biosynthesis were not affected by high $\mathrm{pH}$ values resulting from the 24-hour fermentation (Table III).

Optimization of the age of the seed culture. The optimum age of the seed culture and its physiological state, including the morphological form and metabolic activity, are important factors for efficient production of secondary metabolites (Zou et al., 2011). Inhibitory activities of Streptomyces sp. 8812 metabolites during fermentation cultures that were initiated with seed cultures at various age (at 24,48 or $72 \mathrm{~h}$ ) are presented on Supplementary Fig. 2S. The 24- and 48-hour seed cultures, at late logarithmic phase and middle stationary growth phase, respectively, contributed short lag phases of the submerged cultures. So, the optimal age of seed culture for the production of bioactive metabolites was $24 \mathrm{~h}$ or $48 \mathrm{~h}$. The 72 -hour seed culture needed more time to adapt to new conditions and entered once more the logarithmic growth phase. This resulted in a delay in the reaching the maximum activity of secondary metabolites.

Influence of amino acid supplementation on secondary metabolites activities. Fed-batch culture conducted by supplementation amino acids to the fer- mentation broth is a process aiming at efficient biomolecule production (Zhang et al., 2012). In the present work, the authors studied the stimulatory effect of amino acids on secondary metabolites production by Streptomyces sp. 8812 (Supplementary Fig. 3(A)S-(C)S). Among bioactive metabolites isolated during Streptomyces sp. 8812 fermentation was a novel isoquinoline alkaloid (Solecka et al., 2009a; Solecka et al., 2009b). Biosynthesis of isoquinoline alkaloids in nature starts from three amino acids: L-phenylalanine, L-tyrosine and L-tryptophan (Kegg Pathway Maps, 2014). Thus, these three amino acids were chosen for evaluating their influence on bioactive metabolites activities (HRP inhibition). The rising concentrations of L-tryptophan in the media led to a slight decrease of metabolites activities (Supplementary Fig. 3(A)S). Cultures supplemented with $1 \mathrm{mM}$ L-tyrosine were characterized by high secondary metabolites activities at $24 \mathrm{~h}$ proceeded by a sudden drop (Supplementary Fig. 3(B)S). L-tyrosine at $100 \mathrm{mM}$ concentration had a stimulatory effect on secondary metabolites production. Cultures containing $10 \mathrm{mM}$ L-tyrosine (Supplementary Fig. 3(B) S) as well as $0.1,1,10$ and $100 \mathrm{mM} \mathrm{L}$-phenylalanine (Supplementary Fig. 3(C)S) had comparable secondary metabolites activities to control cultures. In summary, the authors observed a concentration-dependent stimulation of metabolites activities during L-tyrosine feeding. Below the optimal $100 \mathrm{mM}$ concentration of L-tyrosine the activity was equal or lower in respect to the control fermentation.

In bacteria, the three tested amino acids are involved in biosynthesis of phosphorylated nicotinamide adenine dinucleotide $[\mathrm{NAD}(\mathrm{P})]$ and melanin pigment (Arai and Mikami, 1972). Biosynthesis of bioactive metabolites appeared to be closely related to melanin production. Streptomyces sp. 8812 colonies obtained from regenerated protoplasts lacking the ability to produce melanin showed no bioactive metabolites activities (data not shown). The progressive concentration of L-tyrosine clearly influenced melanin production in Streptomyces sp. 8812 (data not shown). It seems that bioactive metabolites have similar precursors as melanin. Probably, when L-tryptophan is added to the Streptomyces sp. 8812 culture, the primary metabolism pathway tends more toward $\mathrm{NAD}(\mathrm{P})$ biosynthesis than secondary metabolites production. In comparison to the tested strain, S. coelicolor produces blue antibiotic-actinorhodin. S. coelicolor mutants, defective at different stages of actinorhodin biosynthesis pathway were all impaired in blue antibiotic production (Hopwood, 2007).

Effect of anion exchange resin on bioactive metabolites production. Bioactive metabolites produced by Streptomyces sp. 8812 were shown to bind to a strong anion exchange resin added to the fermentation broth. 
Substances eluted from the resin added to 24-hour old cultures showed $46.6 \%$ of HRP enzyme inhibition. When resin was added at $48 \mathrm{~h}$ to the fermentation broth, inhibition of the HRP enzyme by eluted substances reached $56.6 \%$.

The authors examined the supernatant from submerged cultures of Streptomyces sp. 8812 supplemented with the anion exchange resin. Addition of the resin to the 24- and 48-hour cultures resulted in a decrease of metabolites activities by $14.5 \%$ and $21.4 \%$, respectively (Supplementary Fig. 4S). In both cases, the microorganism did not produce more bioactive metabolites after the resin was removed from the fermentation broth. Thus, it seems that reduction of the amount of bioactive metabolites in the culture broth is not a stimulating factor for further biosynthesis. An opposite effect of adding resin was observed for cultures which result in pristinamycin (streptogramin family), teicoplanin (glycopeptide family) and proteasome inhibitor NPI-0052 production (Lee et al., 2003; Jia et al., 2006; Tsueng and Lam, 2007). In all mentioned cases, synthesis of bioactive secondary metabolites was shown to increase.

The choice of resin type was made based on its ionic and hydrophobic/hydrophilic properties. Environmental conditions, such as temperature and $\mathrm{pH}$ value, are also important factors for active substance absorption (Casey et al., 2007). It has been well documented that addition of resin to the fermentation broth can reduce feedback repression, eliminate the toxic effect of antibiotics on growth, stabilize the structure of active compounds (prevention from hydrolysis) and, consequently, increase the production of secondary metabolites (Lee et al., 2003; Jia et al., 2006; Tsueng and Lam, 2007). What more, addition of the resin to the medium facilitates further recovery of bound metabolites.

Phylogenetic study of Streptomyces sp. 8812. Sequence analysis for $16 \mathrm{~S}$ rRNA gene using NCBI BLAST algorithm showed 100\% homology of Streptomyces sp. 8812 to Streptomyces capoamus JCM 4734. Phylogenetic analysis of Streptomyces sp. 8812 indicated that its closest relative is Streptomyces capoamus JCM 4734 (98\%) (Supplementary Fig. 5S). S. capoamus is a known producer of antitumor and antifungal compounds (Goncalves da et al., 1968; Hayakawa et al., 1985; Singh et al., 2008).

Mycelium observation under fluorescent microscopy. Mycelium viability and development of Streptomyces sp. 8812 cell clumps are shown in Fig. 1(A)-(F). The clumps are irregular in shape, unlike pellets, and smaller (Denser Pamboukian et al., 2002). In 24-hour seed cultures, single live cells were observed at the periphery of the clumps (Fig. 1(A)-(B)). After $17 \mathrm{~h}$ of production culture live and dead cells were observed in the clumps. At $24 \mathrm{~h}$, the edge of the clumps consisted of thick live mycelium and a decaying center
(Fig. 1(D)). The hyphae inside older clumps were dying, probably due to its high density and low permeability to nutrient substances. At $48 \mathrm{~h}$ and $72 \mathrm{~h}$ dead cells occupied most of the clump area (fluorescent red) (Fig. 1(E)-(F)). Remaining of live cells was seen in the center of the clumps.

Fig. 2(A)-(F) depicts changes in the respiratory level of Streptomyces sp. 8812 under submerged culture. The intensity of red fluorescence is indicative of the respiratory level of bacterial cells. Red areas on the figures represent high respiratory level. Mycelium which formed clumps showed the highest respiratory activity at $17 \mathrm{~h}$ (Fig. 2(C)). High respiratory activity is correlated with high biomass production and active uptake of nutritious substances from the culture broth. After $17 \mathrm{~h}$ of cultivation, cultures enter the stationary phase and a drop in respiratory activity was observed (Fig. 2(D)). At $48 \mathrm{~h}$, there were single red spots seen inside the clumps (Fig. 2(E)). No detectable respiratory activity was observed after $72 \mathrm{~h}$ of cultivation. The primary metabolism of the clumps at $72 \mathrm{~h}$ was low and could not be detected by the CTC fluorescent method (Fig. 2(F)). The CTC assay allows precisely establishing the logarithmic growth phase as well as early and late stationary phase. Using both fluorescent staining methods, the authors determined that the most intensive growth of Streptomyces sp. 8812 mycelium under submerged culture occurs during the first $17 \mathrm{~h}$ of cultivation.

In summary, mycelium observations allowed to establish that the intensity of production of secondary metabolites with DD-carboxypeptidase 64-575 and HRP inhibitory activity by Streptomyces sp. 8812 was correlated with high respiratory level and mycelium viability.

Mycelium enzymatic profiles. Results of the api ${ }^{\oplus}$ ZYM test for Streptomyces sp. 8812 revealed the highest activity of two enzymes: leucine arylamidase and a-chymotrypsin. Both enzymes confirmed that Streptomyces sp. 8812 assimilates nitrogen during the whole fermentation process. Other enzymes from the aminopeptidase group: valine and cystine arylamidases, and trypsin showed low activity at the initial stages of cultivation. Arylamidases and trypsin were active till $48 \mathrm{~h}$ and $120 \mathrm{~h}$, respectively. The api ${ }^{\oplus Y M}$ test revealed low activity of hydrolases, such as esterase or esterase lipase (color intensity 3 ). The activity of esterase and esterase lipase was noted at $0 \mathrm{~h}$ and $24 \mathrm{~h}$ of cultivation, respectively. There was no esterase activity observed after $72 \mathrm{~h}$. Esterase lipase was active till the end of fermentation. Acid phosphatase showed a high level of activity during the first $17 \mathrm{~h}$, between $24 \mathrm{~h}$ and $120 \mathrm{~h}$ its activity was reduced. The api ${ }^{\oplus}$ ZYM results revealed that acid phosphatase could be an enzymatic marker to precisely determine the logarithmic phase of Streptomyces growth. The most intensive phase of 


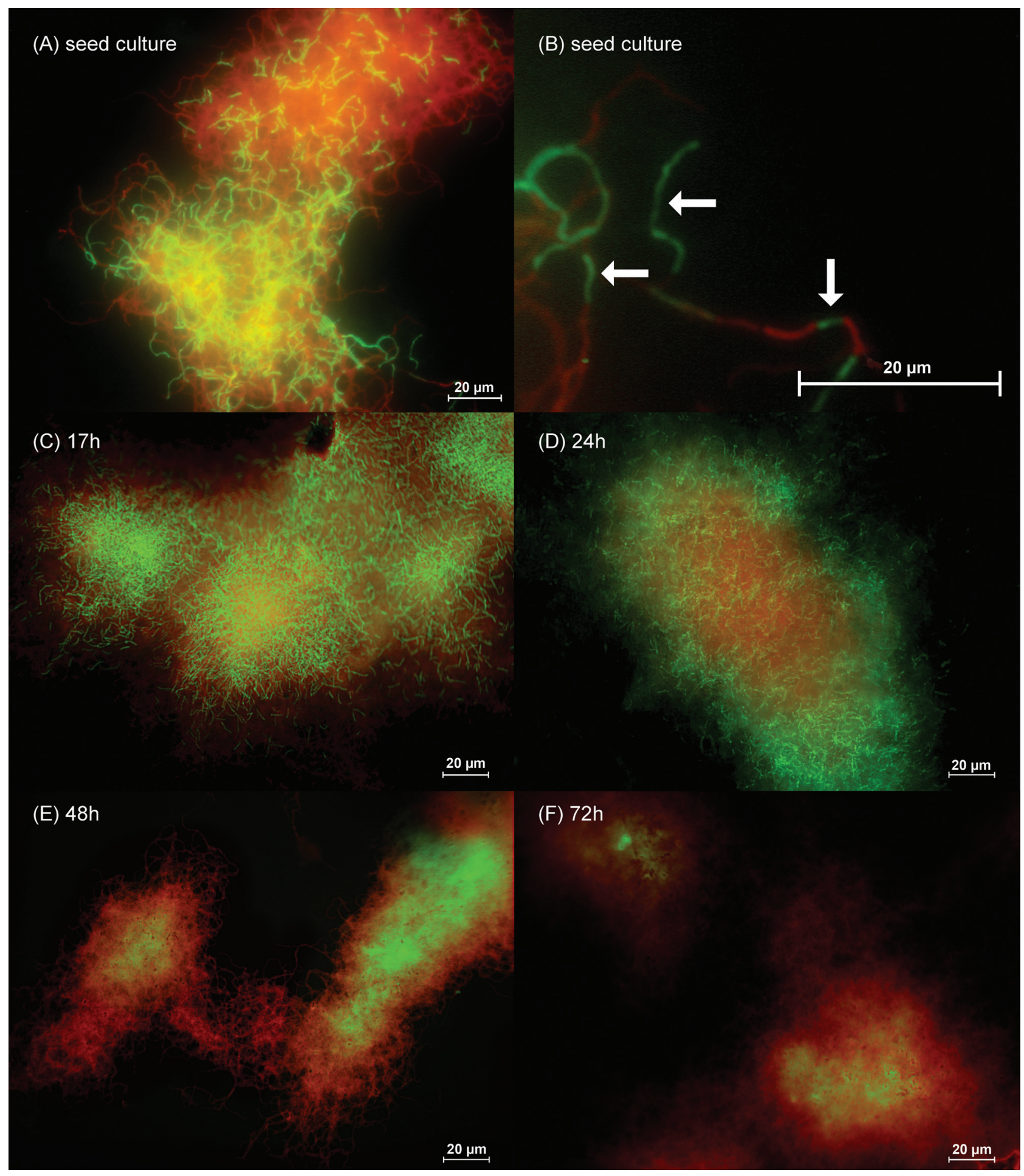

Fig. 1 (A)-(F). Analysis of the development and cell death processes of mycelium in clumps of Streptomyces sp. 8812 in submerged cultures. Images correspond to mycelium stained with SYTO 9 and PI. (B) Single live cells in hyphae from seed culture are indicated with arrows.

Streptomyces sp. 8812 growth was between $17 \mathrm{~h}$ and $24 \mathrm{~h}$ of cultivation. An alkaline phosphatase was active at low level from $48 \mathrm{~h}$ to $120 \mathrm{~h}$. The activity of naphtholAS-BI-phosphohydrolase was high only at $120 \mathrm{~h}$ and could result from release of this enzyme from the cytosol of dead bacterial cells. No activity was detected for lipase, $\beta$-glucuronidase, $\alpha$-glucosidase, $\beta$-glucosidase,
$\mathrm{N}$-acetyl- $\beta$-glucosaminidase, $\alpha$-mannosidase, $\alpha$-fucosidase during the whole process of Streptomyces sp. 8812 fermentation.

Comparison of Streptomyces sp. 8812, S. capoamus and their metabolites. S. capoamus and Streptomyces sp. 8812 cultured for 14 days on ISP2 agar showed similar phenotypic characteristics of aerial mycelium. 


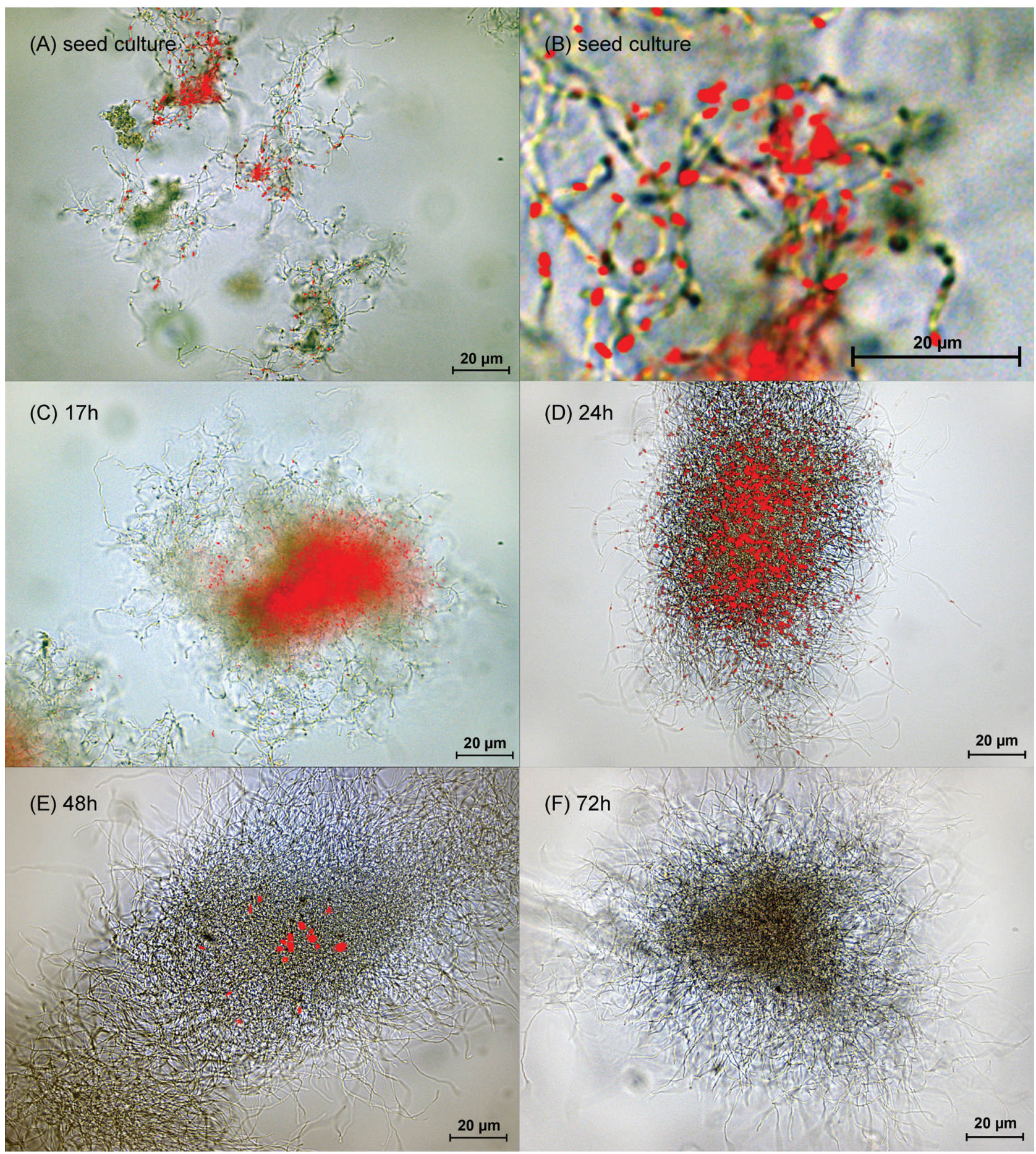

Fig. 2 (A)-(F). Analysis of respiratory processes of mycelium in clumps of Streptomyces sp. 8812 in submerged cultures. Images correspond to mycelium stained with CTC.

When both strains were cultivated in medium $\mathrm{M}$, their secondary metabolites exhibited very similar DDcarboxypeptidase 64-575 inhibitory activities (Supplementary Fig. 6S). Until now, the only antitumor and antifungal metabolites isolated from S. capoamus fermentation broth were capoamycin and ciclacidine (Goncalves et al., 1968; Hayakawa et al., 1985). In the present study, it was determined that S. capoamus produces also DD-carboxypeptidase 64-575 inhibitors.
Conclusions. Conducted studies confirmed that biosynthesis of bioactive metabolites by Streptomyces sp. 8812 is a bioprocess influenced by various external factors ( $\mathrm{pH}$, medium composition, temperature, feeding). Statistical analysis showed that for Streptomyces sp. 8812 increasing amounts of complex nitrogen sources (except Bacto ${ }^{\mathrm{Tm}}$ tryptone) in the tested media was important for biosynthesis of DD-carboxypeptidase 64-575 inhibitors. Higher DD-carboxypeptidase 
64-575 inhibitory activities of secondary metabolites were achieved when the $\mathrm{C} / \mathrm{N}$ ratio was lower. Production of DD-carboxypeptidase 64-575 inhibitors began at the same time as biomass formation (Table III) and reached the maximum level after $48 \mathrm{~h}$. Production of secondary metabolites was not affected by $\mathrm{pH}$ value of the production medium in the measured $\mathrm{pH}$ range of 5.5 to 7.4. The optimal age of seed culture for the production of bioactive metabolites was $24 \mathrm{~h}$ or $48 \mathrm{~h}$. The authors also observed a concentration-dependent stimulation of metabolites activities during L-tyrosine feeding. Phylogenetic analysis of Streptomyces sp. 8812 indicated that its closest relative is S. capoamus JCM 4734 (98\%), whereas sequence analysis for 16S rRNA gene using NCBI BLAST algorithm showed 100\% homology between these two strains.

Development studies of Streptomyces sp. 8812 in submerged culture were performed by means of LIVE/ DEAD $^{\circledR}$ Bac-Light $^{\mathrm{Tm}}$ Bacterial Viability Kit, respiratory activity CTC test and api ${ }^{\oplus}$ ZYM test. Obtained results allowed to separate precisely the logarithmic and stationary phase of growth. Intensive production of secondary metabolites with DD-carboxypeptidase 64-575 and HRP inhibitory activity ceased when the respiratory level and viability of the mycelium dropped. Overall, it was determined that vital functions determine the production of secondary metabolites in Streptomyces sp. 8812.

\section{Acknowledgements}

Financial support by the European Union within the European Regional Development Fund (grant number UDA-POIG.01.03.0114-136/09/08) is gratefully acknowledged.

\section{Literature}

Adam M., C. Damblon, M. Jamin, W. Zorzi, V. Dusart, M. Galleni, A. el Kharroubi, G. Piras, B.G. Spratt and W. Keck. 1991. Acyltransferase activities of the high-molecular-mass essential penicillin-binding proteins. Biochem. J. 279(Pt 2): 601-604.

Adam M., C. Damblon, B. Plaitin, L. Christiaens and J.M. Frére. 1990. Chromogenic depsipeptide substrates for beta-lactamases and penicillin-sensitive DD-peptidases. Biochem. J. 270(2): 525-529.

Arai T. and Y. Mikami. 1972. Chromogenicity of Streptomyces. Appl. Microbiol. 23(2): 402-406.

BD Biosciences. 2006. BD Bionutrients ${ }^{\mathrm{Tm}}$ Technical Manual. Third Edition Revised, pp. 28, 42 and 52. https://www.bd.com/ds/technicalCenter/misc/br_3_2547.pdf, 2015.06.03

Casey J.T., P.K. Walsh and D.G. O'Shea. 2007. Characterisation of adsorbent resins for the recovery of geldanamycin from fermentation broth. Sep. Purif. Technol. 53(3): 281-288.

Chance B. and A.C. Maehly. 1955. Assay of Catalases and Peroxidases. Meth. Enzymol. 2:764-775.

Chen X.S., S. Li, L.J. Liao, X.D. Ren, F. Li, L. Tang, J.H. Zhang and Z.G. Mao. 2011. Production of $\varepsilon$-poly-L-lysine using a novel twostage $\mathrm{pH}$ control strategy by Streptomyces sp. M-Z18 from glycerol. Bioprocess Biosyst. Eng. 34(5): 561-567.
Coenye T., E. Falsen, M. Vancanneyt, B. Hoste, J.R. Govan, K. Kersters and P. Vandamme. 1999. Classification of Alcaligenes faecalis-like isolates from the environment and human clinical samples as Ralstonia gilardii sp. nov. Int. J. Syst. Bacteriol. 49(2): 405-413. De Azeredo L.A., M.B. De Lima, R.R. Coelho and D.M. Freire. 2006. A low-cost fermentation medium for thermophilic protease production by Streptomyces sp. 594 using feather meal and corn steep liquor. Curr. Microbiol. 53(4): 335-339.

Denser Pamboukian C.R., L.M. Guimaraes and M.C.R. Facciotti. 2002. Applications of image analysis in the characterization of Streptomyces olindensis in submerged culture. Braz. J. Microbiol. 33(1): $17-21$.

Desai R.P., T. Leaf, E. Woo and P. Licari. 2002. Enhanced production of heterologous macrolide aglycones by fed-batch cultivation of Streptomyces coelicolor. J. Ind. Microbiol. Biotechnol. 28(5): 297-301. Edwards U., T. Rogall, H. Blocker, M. Emde and E.C. Bottger. 1989. Isolation and direct complete nucleotide determination of entire genes. Characterization of a gene coding for $16 \mathrm{~S}$ ribosomal RNA. Nucleic Acids Res. 17(19): 7843-7853.

Frère J.M., M. Leyh-Bouille, J.M. Ghuysen, M. Nieto and H.R. Perkins. 1976. Exocellular DD-carboxypeptidases-transpeptidases from Streptomyces. Methods Enzymol. 45:610-636.

Genilloud O., I. Gonzalez, O. Salazar, J. Martin, J.R. Tormo and F. Vicente. 2011. Current approaches to exploit actinomycetes as a source of novel natural products. J. Ind. Microbiol. Biotechnol. 38(3): 375-389.

Goncalves da L.O., M.F. Delle, I.L. D’Albuquerque and G.B. Marini Bettolo. 1968. The identification of ciclacidine an antibiotic from Streptomyces capoamus sp. nov. Tetrahedron. Lett. 4: 471-473.

Hayakawa Y., T. Iwakiri, K. Imamura, H. Seto and N. Otake. 1985. Studies on the isotetracenone antibiotics. I. Capoamycin, a new antitumor antibiotic. J. Antibiot. (Tokyo) 38(7): 957-959.

Hopwood D.A. 2007. Streptomyces in nature and medicine. The antibiotic makers. Oxford University Press, New York.

Jia B., Z.H. Jin, Y.L. Lei, L.H. Mei and N.H. Li. 2006. Improved production of pristinamycin coupled with an adsorbent resin in fermentation by Streptomyces pristinaespiralis. Biotechnol. Lett. 28(22): $1811-1815$.

Kegg Pathway Maps. 2014. Isoquinoline alkaloid biosynthesis. http:// www.genome. jp/kegg-bin/show_pathway?map00950, 2015.06.03. Keller and Heckmann LPP. 2006. Assessment Plan for Corn Steep Liquor (CAS \#66071-94-1) in Accordance with the USEPA High Production Volume Chemical Challenge Program. http://www.epa. gov/HPV/pubs/summaries/cornstlq/C16469tp.pdf, 2015.06.03.

Lee J.C., H.R. Park, D.J. Park, H.B. Lee, Y.B. Kim and C.J. Kim. 2003. Improved production of teicoplanin using adsorbent resin in fermentations. Lett. Appl. Microbiol. 37(3):196-200.

Lehmann H.P., K.H. Schosinsky and M.F. Beeler. 1974. Standardization of serum ceruloplasmin concentrations in international enzyme units with $o$-dianisidine dihydrochloride as substrate. Clin. Chem. 20(12): 1564-1567.

Liao X., L.C. Vining and J.L. Doull. 1995. Physiological control of trophophase-idiophase separation in streptomycete cultures producing secondary metabolites. Can. J. Microbiol. 41(4-5): 309-315. Ortiz S.C.A., C.O. Hokka and A.C. Badino. 2007. Utilization of soybean derivatives on clavulanic acid production by Streptomyces clavuligerus. Enzyme Microb Technol. 40(5): 1071-1077.

R Foundation for Statistical Computing. 2013. A language and environment for statistical computing. http://www.r-project org/, 2015.06.03.

Shirling E.B. and D. Gottlieb. 1966. Methods for characterization of Streptomyces species. Int. J. Syst. Bacteriol. 16(3): 313-340.

Singh V., C.K.M. Tripathi and V. Bihari. 2008. Production, optimization and purification of an antifungal compound from Streptomyces capoamus MTCC 8123. Med. Chem. Res. 17(2-7): 94-102. 
Solecka J. and W. Kurzątkowski. 1999. Affinity of exocellular DD carboxypeptidase/transpeptidase from Saccharopolyspora erythraea PZH TZ 64-575 to beta-lactam compounds (in Polish). Med. Dośw. Mikrobiol. 51: 151-165.

Solecka J., R. Lysek, B. Furman, M. Chmielewski and W. Kurzatkowski. 2003. Practical use of DD-peptidase $64-575$ for the assay of inhibition activity of natural and synthetic beta-lactam compounds. Acta Pol. Pharm. 60(2): 115-118.

Solecka J., A. Rajnisz and A.E. Laudy. 2009a. A novel isoquinoline alkaloid, DD-carboxypeptidase inhibitor, with antibacterial activity isolated from Streptomyces sp. 8812. Part I: Taxonomy, fermentation, isolation and biological activities. J. Antibiot. (Tokyo) 62(10): 575-580.

Solecka J., J. Sitkowski, W. Bocian, E. Bednarek, R. Kawecki and L. Kozerski. 2009b. A novel isoquinoline alkaloid, DD-carboxypeptidase inhibitor, with antibacterial activity isolated from Streptomyces sp. 8812. Part II: Physicochemical properties and structure elucidation. J. Antibiot. (Tokyo) 62(10): 581-585.

Solecka J., A. Rajnisz, M. Postek, J. Zajko, R. Kawecki, V. Havlicek, E. Bednarek and L. Kozerski. 2012a. N-acetyl-3,4-dihydroxyL-phenylalanine, a second identified bioactive metabolite produced by Streptomyces sp. 8812. J. Antibiot. (Tokyo) 65(4): 219-221.
Solecka J., J. Zajko, A. Rajnisz and M.A. Postek. 2012b. Searching for novel, bioactive compounds derived from nature (in Polish). Gaz. Farmaceutyczna 1:36-38.

Tsueng G. and K.S. Lam. 2007. Stabilization effect of resin on the production of potent proteasome inhibitor NPI-0052 during submerged fermentation of Salinispora tropica. J. Antibiot. (Tokyo) 60(7): 469-472.

Zhang L.J., Z.H. Jin, X.G. Chen, Q.C. Jin, and M.G. Feng. 2012. Glycine feeding improves pristinamycin production during fermentation including resin for in situ separation. Bioprocess Biosyst. Eng. 35(4): 513-517.

Zhinan X. and C. Peilin. 1999. Enhanced production of avermectin B1a by medium optimization and glucose feeding with Streptomyces avermilitis. Bioprocess Biosyst. Eng. 20(1): 67-71.

Zou X., H.F. Hang, J. Chu, Y.P. Zhuang, and S.L. Zhang. 2009. Oxygen uptake rate optimization with nitrogen regulation for erythromycin production and scale-up from 501 to $372 \mathrm{~m}^{3}$ scale. Bioresour. Technol. 100(3): 1406-1412.

Zou X., W.J. Li, W. Zeng, J. Chu, Y.P. Zhuang and S.L. Zhang. 2011. An assessment of seed quality on erythromycin production by recombinant Saccharopolyspora erythraea strain. Bioresour. Technol. 102(3): 3360-3365. 
